\title{
Phylogeny of Salix subgenus Salix s.l. (Salicaceae): delimitation, biogeography, and reticulate evolution
}

Jie Wu ${ }^{1,2,3}$, Tommi Nyman ${ }^{4}$, Dong-Chao Wang ${ }^{1,2,3}$, George W Argus ${ }^{5}$, Yong-Ping Yang ${ }^{1,2,3^{*}}$ and Jia-Hui Chen ${ }^{1,2,3^{*}}$

\begin{abstract}
Background: The taxonomy and systematics of Salix subgenus Salix s.l. is difficult. The reliability and evolutionary implications of two important morphological characters (number of stamens, and morphology of bud scales) used in subgeneric classification within Salix remain untested, and a disjunct Old-New World distribution pattern of a main clade of subgenus Salix s.l., revealed by a previous study, lacks a reasonable explanation. To study these questions, we conducted phylogenetic analyses based on 4,688 bp of sequence data from four plastid ( $r b c L, t r n D-T$, matK, and $a t p B-r b c L$ ) and two nuclear markers (ETS and ITS) covering all subgenera of Salix, and all sections of subgenus Salix s.l.

Results: Subgenus Salix came out as para- or polyphyletic in both nrDNA and plastid trees. The plastid phylogeny successfully resolved relationships among the major clades of Salix, but resolution within subgenus Salix s.l. remained low. Nevertheless, three monophyletic groups were identifiable in subgenus Salix s.l.: the 'main clade' of subgenus Salix s.l., with New and Old World species being reciprocally monophyletic; the section Triandroides clade; and the subgenus Pleuradenia clade. While nrDNA regions showed higher resolution within subgenus Salix s.l., they failed to resolve subgeneric relationships. Extensive, statistically significant gene-tree incongruence was detected across nrDNA-plastid as well as nrDNA ETS-ITS phylogenies, suggesting reticulate evolution or hybridization within the group. The results were supported by network analyses. Ancestral-state reconstructions indicated that multiple stamens and free bud scales represent the plesiomorphic states within Salix, and that several significant shifts in stamen number and bud scale morphology have occurred.

Conclusions: Subgenus Salix s.l. is not monophyletic, and the evolutionary history of the subgenus has involved multiple reticulation events that may mainly be due to hybridization. The delimitation of subgenus Salix s.l. should be redefined by excluding section Triandrae and subgenus Pleuradenia from it. The evolutionary lability of bud-scale morphology and stamen number means that these characters are unreliable bases for classification. The disjunct Old-New World distribution of subgenus Salix s.l. appears to be linked to the profound climatic cooling during the Tertiary, which cut off gene exchange between New and Old World lineages.
\end{abstract}

Keywords: Salix subgenus Salix, Phylogeny, Biogeography, Reticulate evolution, Character evolution

\footnotetext{
*Correspondence: yangyp@mail.kib.ac.cn; chenjh@mail.kib.ac.cn

'Key Laboratory for Plant Biodiversity and Biogeography of East Asia, Kunming Institute of Botany, Chinese Academy of Sciences, Kunming 650201, P. R. China

2Plant Germplasm and Genomics Center, Kunming Institute of Botany,

Chinese Academy of Sciences, Kunming 650201, P. R. China

Full list of author information is available at the end of the article
}

\section{Biomed Central}

(c) 2015 Wu et al.; licensee BioMed Central. This is an Open Access article distributed under the terms of the Creative Commons Attribution License (http://creativecommons.org/licenses/by/4.0), which permits unrestricted use, distribution, and reproduction in any medium, provided the original work is properly credited. The Creative Commons Public Domain Dedication waiver (http://creativecommons.org/publicdomain/zero/1.0/) applies to the data made available in this article, unless otherwise stated. 


\section{Background}

The genus Salix L. of Salicaceae, commonly known as willows, consists of some 450-520 species, is distributed mainly in the Northern Hemisphere, and is one of the main groups of trees and shrubs in the North Temperate Zone [1-3]. Because of their diversity, and because Salix species form an important resource for innumerable insect and mammalian herbivores [1,3], there is a clear need for understanding the evolutionary history of the group.

Unfortunately, the taxonomy and systematics of Salix have proven extremely difficult because of their dioecious reproduction, simple flowers, common natural hybridization, and large intraspecific phenotypic variation [1,3-5]. Reflecting these difficulties, Salix was once split into at least 35 genera (as reviewed by Argus [6]), but numerous molecular-phylogenetic studies have shown that Salix is a robust monophyletic group that encompasses all of the putative generic segregates [7-11]. This indicates that Salix is a natural group that should not be further split at the generic level, and so some recent systems e.g., $[1,12]$ have opted to treat segregate genera, such as Chosenia and Toisusu, as members of Salix.

A widely used Salix classification system was proposed by Skvortsov in 1968 ([13]; revised and translated into English in 1999 [3]). In this system, he divided the Salicaceae into three genera, Populus, Chosenia, and Salix. Within Salix, Skvortsov recognized three subgenera: Salix, Chamaetia, and Vetrix. He also suggested that the subgenera Urbaniana and Longifoliae could be recognized, but did not do so. Because subgenus Salix as used by Skvortsov was later divided into several smaller subgenera, for the convenience of discussion, we will below refer to it as subgenus Salix s.l.

Subgenus Salix s.l. is primarily distributed in the warm Temperate Zone and partially in tropical regions (Figure 1) [3]. The subgeneric and especially sectional division of subgenus Salix s.l. is in a chaos: section names and their delimitation in different systematic treatments differ, a main reason being that most systems are based on localized floras. Furthermore, different systems of subgenus Salix s.l. (as well as Salix on the subgeneric level) use bud-scale morphology (margin free or connate) and the number of stamens (two or multiple) as important criteria $[1,3,4]$, but whether taxa classified according to these two traits are reasonable remains unknown.

After summarizing the main recent Salix systems $[1-3,12]$, we found that subgenus Salix s.l. contains approximately 128 species. Most of them (109) are distributed in the Old World, and are placed into seven sections: Tetraspermae, Urbanianae (= subgenus Pleuradenia), Wilsonia, Pentandrae, Triandrae, Octandrae, and Salix (sometimes split into Subalbae and Salix). Only 19 species are found in the New World; these belong to the five sections Longifoliae (= subgenus Longifoliae), Humboldtianae, Floridanae, Maccallianae, and Salicaster. However, while each section in this classification is found only in the New or Old World, morphological

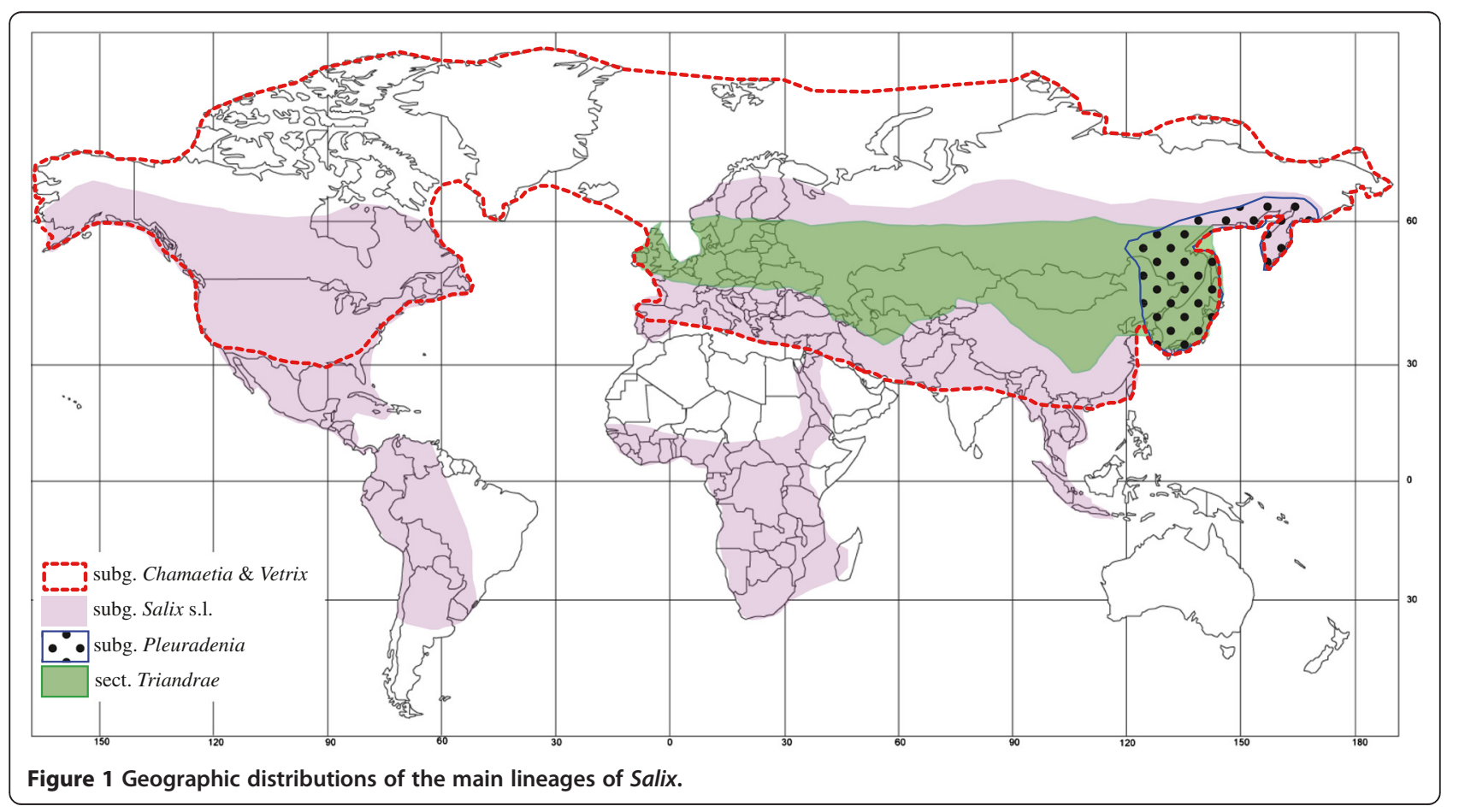


differences among species and sections are small. For example, the Old World sections Tetraspermae and Pentandrae appear to be closely related to the New World sections Humboldtianae and Salicaster, respectively, and Argus [1] treated section Pentandrae as a synonym of Salicaster, and section Tetraspermae as a synonym of Humboldtianae. Skvortsov's sections Humboldtianae and Pentandrae likewise contain both $\mathrm{New}$ and Old World species.

Skvortsov [3] postulated that the subgenera Chamaetia and Vetrix are more closely related to each other than either is to subgenus Salix, and that subgenus Salix is a natural group, having the most in common with Populus and exhibiting "primitive" features in the structure of bracts, nectaries, androecium, and gynoecium. However, recent molecular-phylogenetic studies have cast doubt on the monophyly of subgenus Salix s.l. $[8,9,11]$ and, based on morphological characters, the group has also been divided into at least five widely accepted subgenera: Chosenia and Pleuradenia, each containing only one species [12]; Longifoliae, with 8 species [1]; Protitea, with 33 species [1,12,14]; and Salix, with 85 species [1] (we refer to Argus's [1] subgenus Salix as subgenus Salix s.str., in contrast to Skvortsov's subgenus Salix s.l.). In Kimura's [14] Salix system, subgenus Chosenia is a synonym of subgenus Pleuradenia.

The composition and further division of subgenus Salix s.l. is therefore a central issue in the systematics of Salix. However, sparse taxon sampling and use of low numbers of DNA markers in previous molecularphylogenetic studies have led to restricted understanding of the classification and systematics within the group $[9,15]$. Our former study [9] also revealed a disjunct distribution pattern in the main clade of subgenus Salix s.l., so that Old and New Word species formed robust clades. By contrast, the subgenera Chamaetia and Vetrix, which also formed a robust monophyletic group, did not present similar trans-continental disjunctions in their (widely overlapping) geographic ranges (Figure 1). The low density of sampling of subgenus Salix s.l. representatives in the study unfortunately left the reliability of, and the reasons for, the disjunct distribution pattern unknown.

In this study, we examined representatives covering all major clades of Salix and all sections of subgenus Salix s.l. using six DNA regions: external transcribed spacer (ETS) and internal transcribed spacer (ITS) regions of nuclear ribosomal DNA (nrDNA), and partial sequences of the $r b c L$ and matK genes, and $a t p B-r b c L$ and $\operatorname{trn} D-T$ non-coding spacers of plasmid chloroplast DNA. The main aims of our study were to: (1) establish a phylogeny of Salix subgenus Salix s.l. in order to evaluate the correctness and utility of present classification systems, (2) identify possible inconsistencies between
nrDNA and plastid phylogenies, and to explore possible causes for it, (3) estimate the divergence times of the major clades of Salix, in order to explain their current distribution patterns, and (4) assess the value of the two most important characters used in classification and systematics of Salix, i.e., bud scale morphology and stamen number.

\section{Results}

\section{Sequence variation}

The most variable of the six regions sequenced is ETS, with the highest average sequence divergence value and proportion of parsimony-informative characters, while the other nrDNA region, ITS, also shows high variation but much less than ETS (Table 1). Sequence variation in the plastid regions is lower than for nrDNA, and matK shows the least variation. The plastid $\operatorname{trn} D-T$ region possesses the most indels and highest indel diversity in Salix, while indels are absent from matK and $r b c L$ (Table 1). Detailed alignment and sequence characters' information for the regions sequenced, and tree statistics from the phylogenetic analyses, are listed in Table 1.

\section{Phylogenetic trees and networks}

The ILD test comparing the ETS and ITS datasets indicated significant incongruence $(P=0.002)$, and many of the incongruent clades were well supported ( $\mathrm{BS} \geq 70 \%$ ). Significant incongruence likewise was detected between the nrDNA and plastid datasets (both $P<0.001$ ), but not among the plastid regions (all $P>0.2$ ). Therefore, phylogenetic analyses were performed for ETS, ITS, and combined plastid datasets, but not for combined nrDNA or combined nrDNA and plastid datasets.

While the topologies of nrDNA and plastid phylogenies are significantly incongruent, Salix was resolved as robustly monophyletic in all trees (Figure 2 ). The combined plastid tree (Figure 2C) successfully resolved relationships of major clades of Salix, and divided the genus into two well-supported clades ( $F$ and $G$ ) as well as many smaller subclades (A, B, C, F1, F2, and H). Subgenus Salix s.l. is not a monophylum in the plastid tree, although the majority of its species grouped into a large clade (F). Resolution inside the F clade is low, but Old and New World species are reciprocally monophyletic (subclades F1 and F2, respectively). Subgenus Pleuradenia and section Triandrae fell out this main F clade of subgenus Salix s.l.: two species of the latter (S. triandra and $S$. triandroides) formed a robust monophyletic group (clade B) as sister to a clade formed by subgenus Pleuradenia (clade A) and a robust monophyletic group (clade $\mathrm{H}$ ) that includes all species of subgenera Chamaetia and Vetrix as well as three species of section Salix (S. bangongensis, S. qinghaiensis, and S. sericocarpa) and one species of section Triandrae (S. songarica). Among the 
Table 1 Characteristics of data matrix and tree statistics from the ML and MP analyses

\begin{tabular}{|c|c|c|c|c|c|c|c|}
\hline & ETS & ITS & $r b c L$ & $\operatorname{trn} D-T$ & $a t p B-r b c L$ & matK & Combined plastid \\
\hline No. of taxa & 57 & 57 & 56 & 56 & 56 & 56 & 56 \\
\hline Aligned length & 304 & 682 & 1119 & 1017 & 760 & 787 & 3683 \\
\hline GC\% & 63.0 & 64.5 & 43.6 & 32.3 & 28.3 & 33.5 & 35.2 \\
\hline No. (\%) of variable characters & $136(44.7)$ & $157(23.0)$ & $77(6.9)$ & $95(9.3)$ & $60(7.9)$ & $54(6.9)$ & $286(7.8)$ \\
\hline $\begin{array}{l}\text { No. (\%) of parsimony-informative } \\
\text { characters }\end{array}$ & $71(23.4)$ & $57(8.4)$ & $34(3.0)$ & $43(4.2)$ & $24(3.2)$ & $20(2.5)$ & $121(3.3)$ \\
\hline $\begin{array}{l}\text { Average sequence divergence } \\
\text { with/without outgroup }\end{array}$ & $0.054 / 0.043$ & $0.022 / 0.015$ & $0.008 / 0.008$ & $0.011 / 0.009$ & $0.008 / 0.007$ & $0.006 / 0.004$ & - \\
\hline No. of indel sites/indel events in Salix & $6 / 6$ & $16 / 13$ & - & $209 / 33$ & $49 / 19$ & - & - \\
\hline No. of haplotypes with indels in Salix & 6 & 15 & - & 25 & 11 & - & - \\
\hline Indel diversity in Salix & 0.388 & 1.345 & - & 6.898 & 1.111 & - & - \\
\hline No. of MP trees & 8 & 3 & 10 & 8 & 10 & 8 & 5 \\
\hline Tree length (MP) & 181 & 180 & 126 & 92 & 60 & 57 & 347 \\
\hline $\mathrm{Cl}(\mathrm{MP})$ & 0.762 & 0.850 & 0.837 & 0.815 & 0.883 & 0.982 & 0.827 \\
\hline RI (MP) & 0.874 & 0.909 & 0.935 & 0.917 & 0.945 & 0.991 & 0.909 \\
\hline HI (MP) & 0.238 & 0.150 & 0.163 & 0.185 & 0.117 & 0.018 & 0.173 \\
\hline
\end{tabular}

subgenera consistently split from subgenus Salix s.l., Pleuradenia was resolved as monophyletic; subgenus Longifoliae was likewise monophyletic (clade C), but it was nested within the main Salix s.l. clade.

In contrast to the plastid tree, nrDNA ETS and ITS trees failed to resolve relationships of major clades of Salix, but they also indicate that subgenus Salix s.l. is not monophyletic (Figure 2A,B). Both of the nuclear trees exhibited a large basal polytomy, but especially the ETS tree shows higher resolution within subgenus Salix s.l. A large clade consisting of some 27 or 28 Old World subgenus Salix s.l. species (S. sphaeronymphoides falls outside this clade in the ITS tree) and two New World species (S. lucida and S. floridana) was present in the

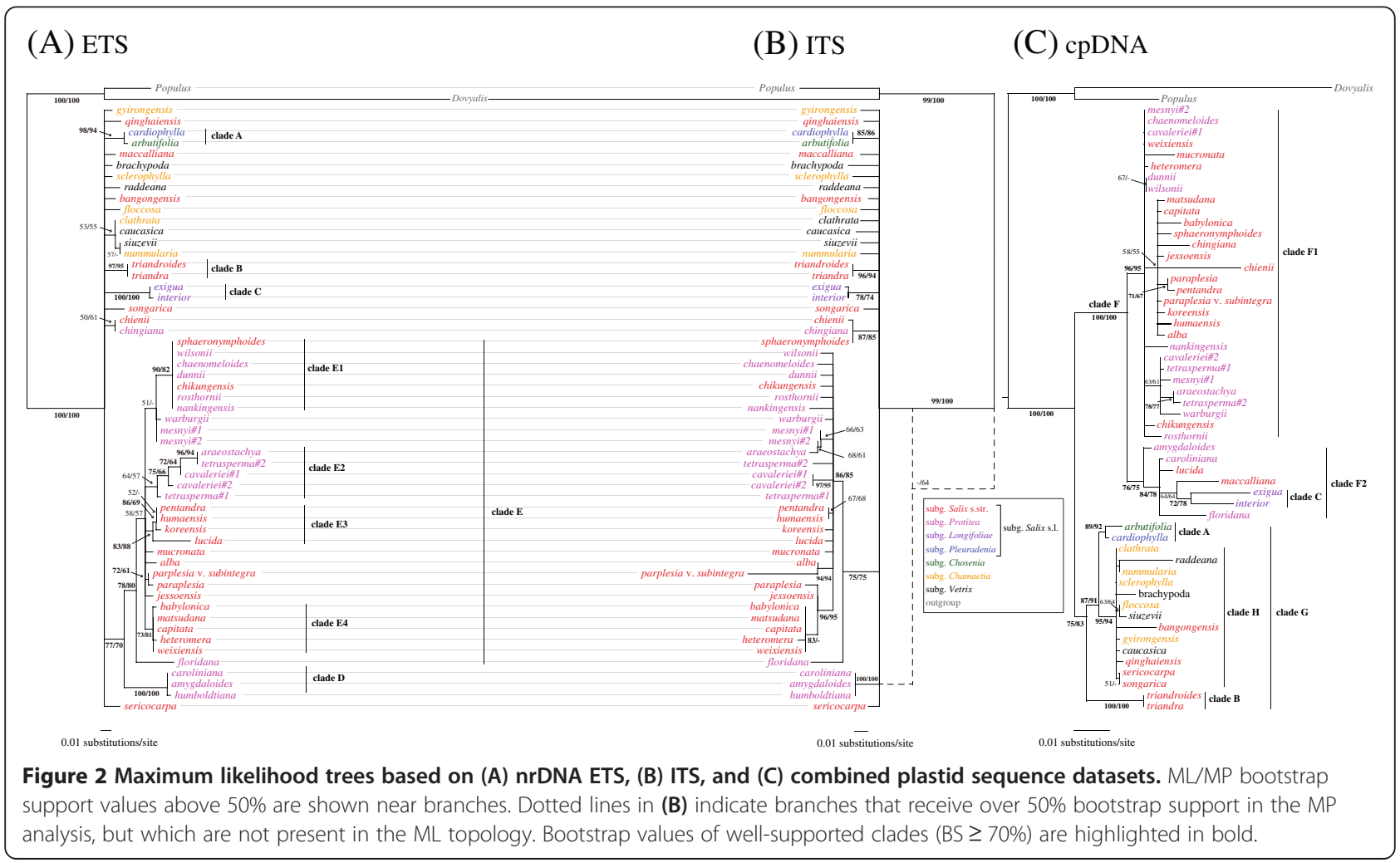


nrDNA trees (clade E in Figure 2). Several well-supported subclades of clade $\mathrm{E}$ were recognized (E1-E4), but most of them are incongruent, except for clade E4, which consists of species of section Salix (Figure 2). Species of section Humboldtianae form a monophyletic, well-supported sister group (clade D) of clade E in the ETS tree. In the ITS tree, section Humboldtianae is sister to the remaining Salix taxa, but this relationship is poorly supported (MP $\mathrm{BS}=64 \%$ ) and present only in the MP tree (Figure 2B).

Numerous (at least seven) reticulation events were detected in the network analysis (Figure 3). Notably, all of them are associated with taxa belonging to clade $\mathrm{F}$ of subgenus Salix s.l. in the plastid tree, whereas no reticulation events were detected in clade G (Figure 2C).

\section{Divergence times of the main clades of Salix}

The crown-group age of Salix (node 1 in Figure 4) was estimated to be $43.87 \mathrm{Ma}$ (95\% HPD: 37.15-48.42 Ma), and the divergence time of the main clade of New and Old World subgenus Salix s.l. (node 2) was estimated at $33.99 \mathrm{Ma}$ (95\% HPD: 24.77-44.06 Ma). The divergence times of other main clades of Salix, estimated based on combined plastid datasets, are shown in Figure 4.

\section{Character evolution}

Our ancestral-state reconstructions show that multiple stamens and free bud scales represent the plesiomorphic states within both the genus Salix and the main clade of subgenus Salix s.l., while a shift to two stamens and connate bud scales occurred at the base of the lineage leading to Chamaetia and Vetrix (Figure 5). However, groups defined by the alternative states of neither character are monophyletic, because the number of stamens has repeatedly been reduced from multiple to two, and connate bud scales have originated multiple times convergently. Also reversals to the plesiomorphic condition in both characters can be identified across the tree.

\section{Discussion}

Taxonomic and systematic implications

The monophyly of the genus Salix in our results is consistent with inferences from previous phylogenetic analyses of morphological and molecular data e.g., $[5,7,9,16,17]$, and support the view that Salix is a natural group that should not be further split at the generic level.

The species of subgenera Chamaetia and Vetrix fall into a robust monophyletic group in our plastid gene trees, but resolution within the clade is low, and the subgenera are not reciprocally monophyletic. This result is consistent with previous research $[8,9,16]$, and supports the merging of Chamaetia with Vetrix [18]. Nevertheless, although it is clear that subgenus Chamaetia is morphologically closer to subgenus Vetrix than to subgenus Salix, it may be taxonomically useful to treat them as separate subgenera until more representatives of these two subgenera have been included in molecular studies.

In the subgenera divided from subgenus Salix s.l., Pleuradenia was established by Kimura in 1988 and consisted of S. arbutifolia and S. cardiophylla [14], to which he gave generic rank (Chosenia and Toisusu, respectively) in 1928 [19]. Ohashi [12] recognized them as two subgenera (Chosenia and Pleuradenia, respectively). In our results, S. arbutifolia and S. cardiophylla are consistently placed as sister species, which is consistent with
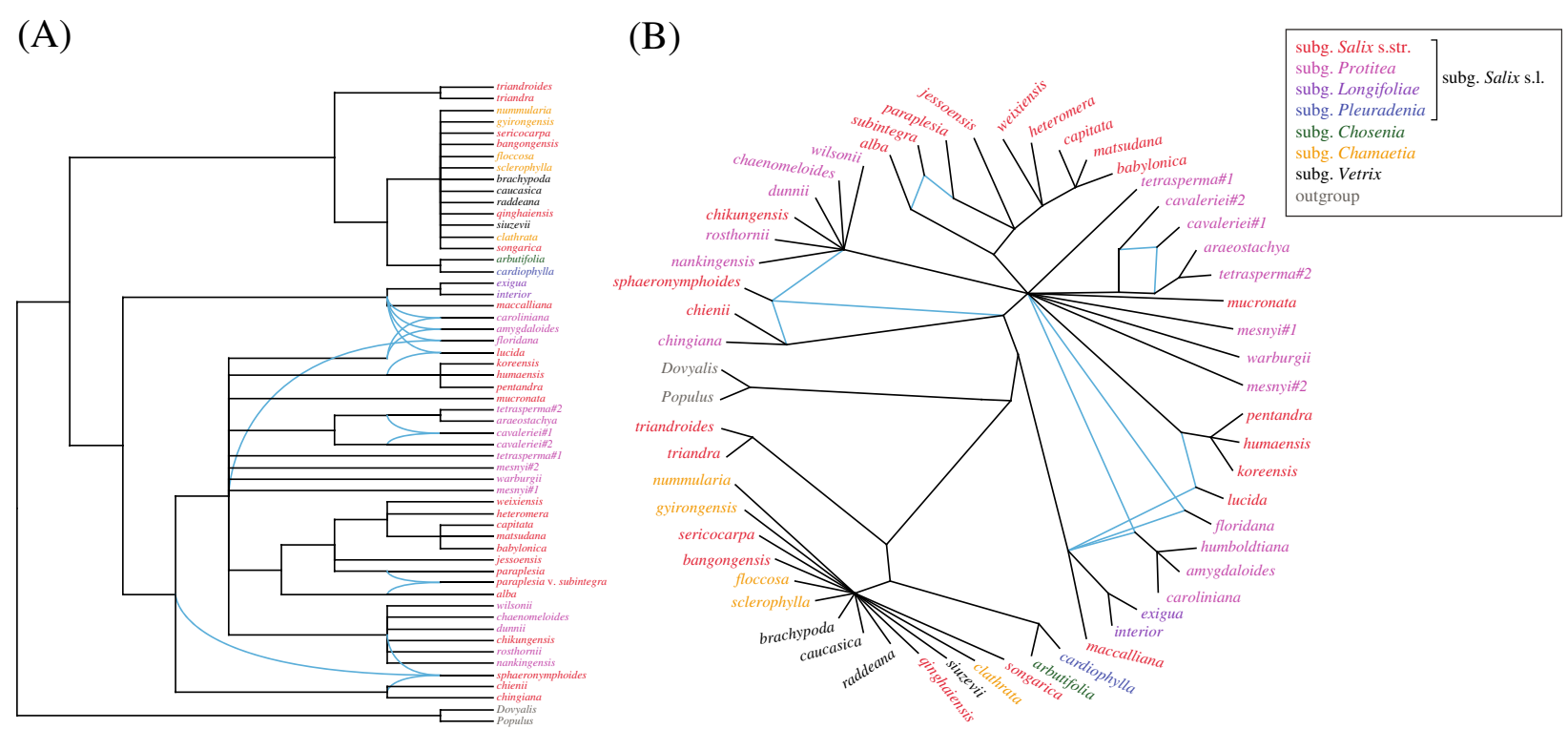

Figure 3 Phylogenetic network of nrDNA ETS, ITS, and combined plastid ML trees with inferred reticulation events, drawn as (A) rectangular and $(B)$ radial cladograms. 


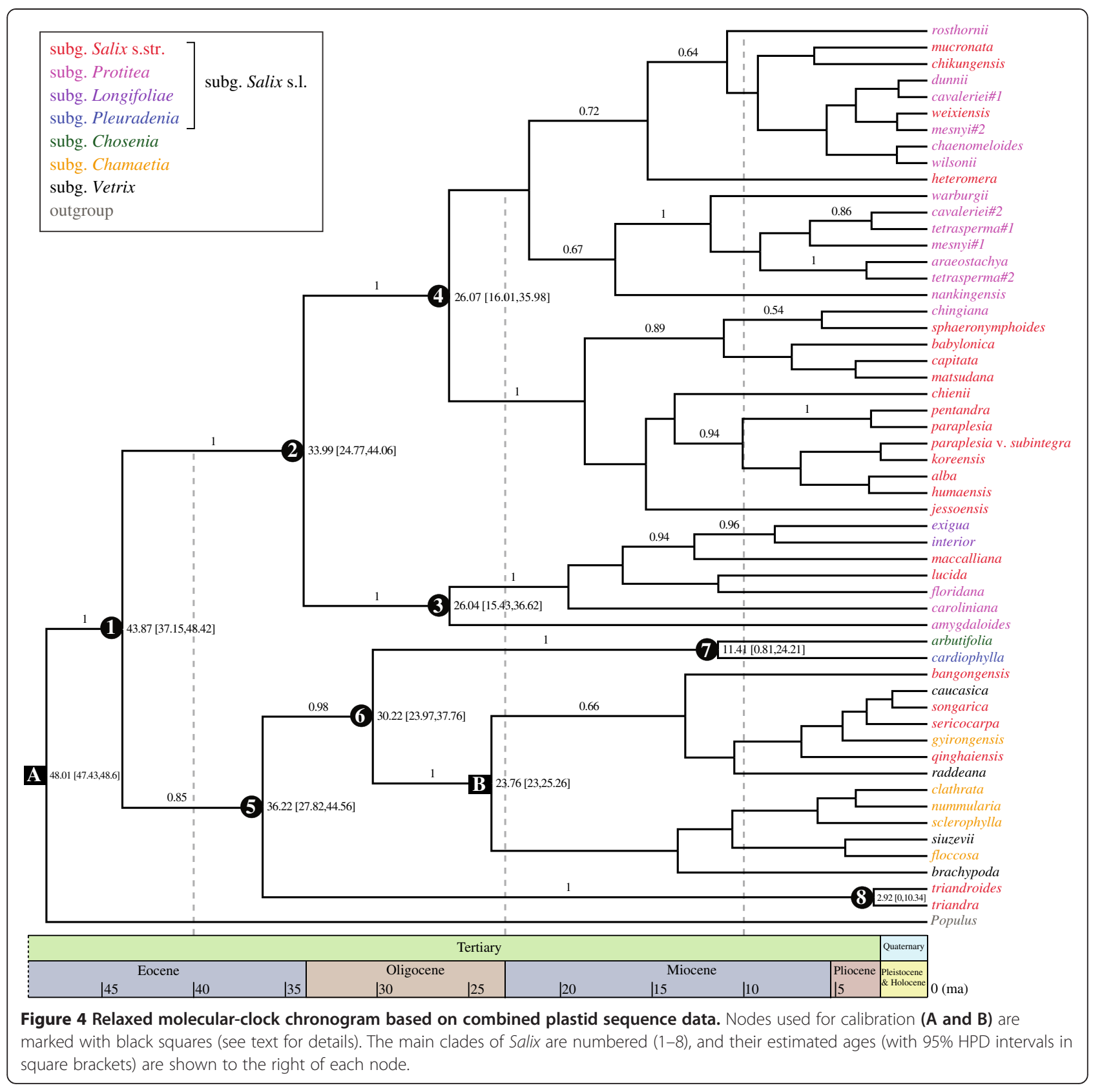

former studies $[9,15,20]$ and their morphological affinities (both possess pendulous catkins, have connate stamens with bracts at their base, and have deciduous stigmas after flowering), and supports the grouping of both species in subgenus Pleuradenia Kimura.

The American subgenus Longifoliae was established by Argus [21] based on molecular, anatomical, developmental, chemical, genetic, and morphological evidence. Our results indicate that Longifoliae constitutes an independent lineage of Salix, but since it is nested inside the subgenus Salix s.l. clade in our plastid trees, its subgeneric rank needs further confirmation in the future. The subgenera Salix s.str. and Protitea are clearly poly- or paraphyletic in our results. Although some subclades were recognized for both of these subgenera, the subclades seem not to follow any distribution pattern nor share any obvious morphological traits, and no sections were recognized as monophyletic.

Previous studies have indicated that $S$. triandra is in some traits somewhat unique as compared to other Salix species, and that it might therefore constitute a distinct subgenus $[9,22]$. However, these investigations both included S. triandra as the sole representative of section Triandrae. Our analysis, which included all three species of section Triandrae, reveal that the group, as currently defined [12], is not monophyletic, because S. songarica 


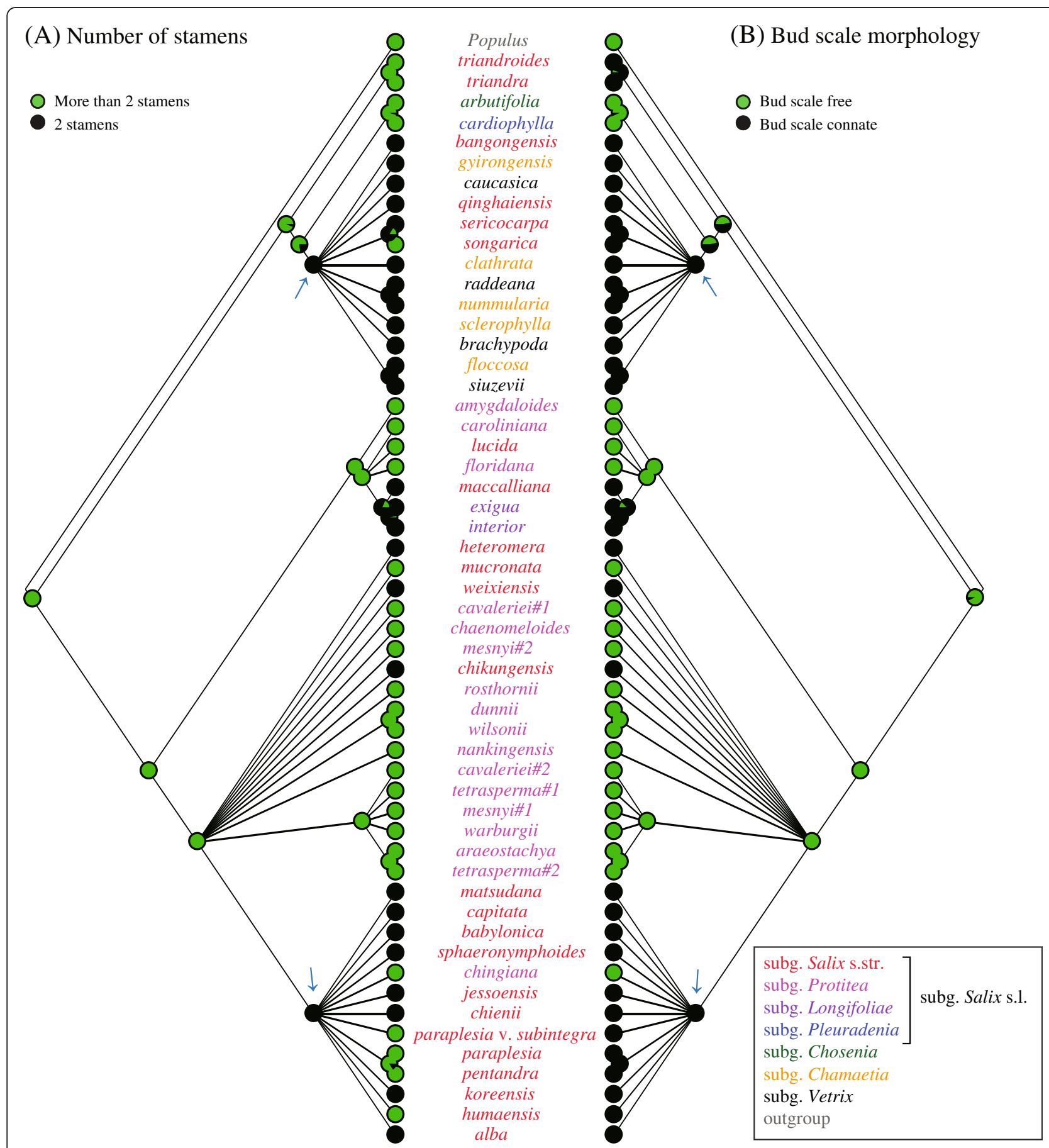

Figure 5 Ancestral state reconstruction of (B) bud scale morphology and (A) number of stamens, according to maximum likelihood optimization of states across the ML tree based on combined plastid datasets. Arrows indicate nodes with major character state shifts.

falls outside the $S$. triandra-S. triandroides clade (clade B in Figure 2). Section Triandrae is defined mainly by the presence of 3 stamens, but this character differs among and within species. Most flowers of section Triandrae have 3 stamens, but $S$. triandra occasionally has 2 , 4, or 5 stamens, while $S$. songarica sometimes possesses 4 stamens [2], indicating that this section cannot be reliably defined based on stamen number. We suggest treating section Triandrae as a subgenus, but delimited so that it includes only $S$. triandra and $S$. triandroides.

Four species of Salix s.l. (i.e., S. qinghaiensis, S. sericocarpa, S. bangongensis, and the aforementioned S. songarica) are grouped with the subgenera Chamaetia and Vetrix in the plastid tree; in the nrDNA tree, these 
species are placed in a polytomy outside the large subgenus Salix s.l. clade. The network analysis (Figure 3) indicates no reticulations involving these species, suggesting that their positions are congruent in all phylogenetic trees, and that they have a closer relationship with subgenera Chamaetia and Vetrix than with subgenus Salix s.l. All of these species have two stamens, except for S. songarica, which has three (a reversion as indicated by our character-evolution analysis, Figure 5). This indicates that these four species should be treated as members of subgenera Chamaetia or Vetrix.

\section{Phylogenetic conflict}

Phylogenetic incongruence between different sequence datasets has been demonstrated in many plant groups $[23,24]$. As summarized by Zou and Ge [24], stochastic (sampling) errors, systematic errors (long-branch attraction, i.e., long branches tend to group together in MP analyses even if they are distantly related [25]), and biological factors could give rise to gene-tree conflicts.

Methods usually used to diminish the first two conflicts include increasing the number of characters and using an appropriate phylogenetic analysis method [24]. We employed six DNA markers to increase character number, and analyzed the data using both MP and ML, so stochastic and systematic errors can both be excluded as reasons for the gene-tree conflicts observed. Instead, the incongruent phylogenies may be caused mainly by biological factors, including horizontal gene transfer (HGT), undetected paralogs, incomplete lineage sorting (ILS), and hybridization/introgression [23,26]. Chloroplasts seem essentially immune to HGT (as reviewed by Richardson and Palmer [27]), meaning that HGT is not a likely cause for the gene-tree discordance. Ribosomal genes exhibit high copy numbers [28], and concerted evolution, which tends to homogenize sequences of rDNA arrays, may be incomplete [28,29]. ITS and ETS sequences likewise have relatively high levels of homoplasy [28]. This is exactly the case in our results (Table 1), so it is possible that ortholog/paralog confusion and a higher level of homoplasy caused part of the detected gene-tree conflicts; further studies are needed to clarify these issues. However, because lineage sorting of ancestral genotypes is a stochastic process, it is not expected to follow any geographic pattern [30]. By contrast, some of the clades in our trees clearly reflect geographic patterns (e.g., Old and New World species of the main clade of subgenus Salix s.l. form reciprocally monophyletic groups in the plastid tree). Therefore, unlike Hardig et al. [10], we think ILS is most likely insufficient to explain the gene-tree incongruence.

Morphological and molecular studies have shown that hybridization among Salix species is an important source of variability $[1,3,4]$, and that hybrids are frequently able to backcross and to introgress [31-33]. Our network analysis indicated that reticulate evolution is common in subgenus Salix s.l., suggesting that hybridization/ introgression is the main reason for the extensive genetree conflicts. For example, Clade $\mathrm{E}$ in the nrDNA trees (Figure 2A,B) consists of subgenus Salix s.l. species; all but two (S. floridana and S. lucida) are Old World species, with $S$. floridana being sister to the remaining species of this clade. However, the placement of these two New World species conflicts with the plastid tree, in which they are nested in the New World clade within subgenus Salix s.l. Because there was no gene flow between the ancestors of the New and Old World lineages of subgenus Salix s.l. (see Discussion below), this may be primarily due to ancient hybridization as indicated by the network analysis (Figure 3). This is consistent with morphological traits: S. floridana resembles the Old World subgenus Salix s.l. species S. tetrasperma and $S$. rosthornii, and it is assumed to be a relict or a descendant of the Arcto-Tertiary flora [34]. Furthermore, S. lucida is similar to the Old World subgenus Salix s.l. species $S$. pentandra in leaf and catkin morphology [34]. Likewise, the other conflicting clades can also explained by hybridization; these species include $S$. caroliniana, S. amygdaloides, S. cavaleriei, S. paraplesia var. subintegra, and S. sphaeronymphoides.

\section{Biogeographic implications}

The most striking distribution pattern of Salix revealed by our molecular- phylogenetic study is the New-Old World disjunction within the main clade of subgenus Salix s.l. in the plastid tree. Similar disjunctions are not found within the subgenera Chamaetia and Vetrix, despite the fact that they are also distributed widely in across the Northern Hemisphere. The divergence times of the main clade of New and Old World subgenus Salix s.l. and subgenera Chamaetia and Vetrix were estimated at 33.99 (about early Oligocene) and 23.76 mya (about lower Oligocene), respectively. During the middle of the upper Oligocene, the physical continuity of the Bering Land Bridge (BLB) is certain, but questioned for the North Atlantic Bridge (NALB) [35]. However, while paratropical groups presumably could exchange rather freely across the BLB during the early Paleocene and Eocene, intercontinental dispersal of such thermophilic elements was increasingly restricted by subsequent climatic cooling [35,36]. Extant representatives of subgenus Salix s.l. mostly inhabit sub-tropical and partially tropical regions (Figure 1), and it is therefore reasonable to assume that the subgenus was ancestrally adapted to temperate conditions, and that they could disperse freely between the New and Old Worlds via the BLB only during their early history. On the other hand, willow seeds have fine hairs and can travel hundreds of kilometers by air, and 
Salix species in the Svalbard archipelago have colonized the islands by repeated long-distance dispersal from Scandinavia [37]. Hence, the possibility of dispersal between the New and Old Worlds by island-hopping via the NALB during the Eocene and Oligocene boundary cannot be ruled out. However, regardless of the exact route taken, subsequent climatic cooling in the Tertiary cut off the floral exchange between New and Old World lineages of subgenus Salix s.l., resulting in the intercontinental disjunction pattern seen in our phylogenetic trees.

By contrast, most species of the subgenus Chamaetia and some species of Vetrix are Arctic-Alpine taxa that are well adapted to cold, hostile environments. Floristic migrations over the BLB were primarily controlled by climate in most of the Cenozoic [38,39], and large parts of the Arctic and Subarctic in northwest America and eastern Siberia (i.e., Beringia) were never glaciated $[38,40]$. These factors indicate that the climatic cooling of the late Tertiary [36] facilitated intercontinental gene exchange within the cold-adapted subgenera Chamaetia and Vetrix, and also resulted in widely Holarctic distributions in many extant species within subgenus Chamaetia.

The S. cardiophylla-S. arbutifolia (i.e., subgenus Pleuradenia Kimura) clade has a limited distribution area in northeastern Asia (Figure 1). The crown age of it was estimated at 11.41 mya (95\% HPD: 0.81-24.21 mya). The common ancestors of this group most likely diverged in northeastern Asia, and when and after they diverged, there were factors limiting north-to-south floristic exchange in central Asia (temperature and moisture) and east-to-west exchange across central China (moisture) [35]. Therefore, the ancestors of this clade could not disperse to Eurasia and the New World.

\section{Character evolution}

The number of stamens has been thought to be a key trait reflecting the evolutionary history of Salix, and it is still one of the main characters used in the classification of Salix at the subgeneric level [1,3,12,41,42]. Stamen number within Salix varies from 2 to 12, with filaments being either free or partly to completely connate [2], but only 49 Salix species $(\sim 10 \%)$ have multiple stamens [1]. Our results revealed a trend of reduction in stamen number from multiple to two in several different lineages of Salix. As a result, stamen number states are paraphyletic across the phylogenetic tree, and the frequent changes indicate that the number of stamens constitutes an unreliable basis for Salix classification.

Interestingly, it seems that stamen number is related to species diversity in different Salix lineages, because the subgenera Chamaetia and Vetrix, which together account for $\sim 73 \%$ of the species within the genus, all have two stamens. Pollination in Salix is almost exclusively performed by insects [3], and insect pollination predominates also in the few species that are ambophilous [43]. Because male flowers reward biotic pollinators with both pollen and nectar, while females only produce nectar, some biotic pollinators might discriminate against female flowers, resulting in reduced female fertility and favoring the evolution of wind pollination or pollination by less-discriminating pollinators $[44,45]$. Pollinator discrimination can also be avoided by female flowers by producing more nectar than male flowers [46-48]. Here we speculate that the reduction of stamen number might be an alternative adaptation, in that it may reduce pollen production and therefore might be favored by natural selection. Reductions in the number of stamens may also allow more precise pollen transfer by specialist insect pollinators and, consequently, lead to less expense of pollen and nectar [49-51]. This type of selective advantage of specialist pollination may have played an important role in the diversification of Salix, and could partly result in unequal species diversity in different Salix lineages. Further efforts are needed to test this hypothesis.

Bud scale morphology is another key characteristic used in traditional subgenus-level classifications of Salix. About 91\% of Salix species (including all species of subgenera Chamaetia and Vetrix) have connate bud scales. Our ancestral-state reconstruction showed that bud scale margins changed from free to connate independently in different lineages. Our divergence-time estimates indicate that Salix originated approximately in the middle of the upper Oligocene. As mentioned above, the Tertiary was a time of cooling climates [52], and connate bud scales could protect the apical meristem more effectively than free ones; therefore, the presence of connate bud scales could have been selectively favored in cold-adapted lineages such as the subgenera Chamaetia and Vetrix.

\section{Conclusions}

Our nrDNA and plastid trees revealed that, while the genus Salix constitutes a robust monophyletic group, this is not the case for subgenus Salix s.l. Among the subgenera previously split from subgenus Salix s.l., only Longifoliae and Pleuradenia are supported as being monophyletic. The delimitation of subgenus Salix s.l. should be redefined so that sections Triandrae and Urbanianae (= subgenus Pleuradenia), as well as a few additional species (S. bangongensis, S. qinghaiensis, $S$. sericocarpa, and S. songarica), are excluded from it. Our phylogeny-based ancestral-state reconstructions indicated that the presence of multiple stamens and free bud scales are plesiomorphic within Salix, but also that shifts from multiple to two stamens and from free to connate bud-scale margins have occurred repeatedly; this means 
that these traditionally used morphological traits constitute an unreliable basis for subgenus-level classifications.

Extensive gene-tree conflicts between nrDNA and plastid phylogenies as well as between nrDNA ETS and ITS regions primarily appear to be due to hybridization and reticulate evolution. This interpretation is in line with the recent results of Percy et al. [5], who found widespread sharing of plastid haplotypes and even signs of possible trans-specific selective sweeps within Salix. In the plastid tree, Old and New World representatives of the main clade of subgenus Salix s.l. are reciprocally monophyletic; our biogeographic analysis based on a fossil-calibrated phylogenetic tree indicates that the disjunction results from climatic cooling during the late Tertiary, which cut off northern dispersal routes and, hence, genetic exchange between the continents. By contrast, in the more cold-tolerant subgenera Chamaetia and Vetrix, continuous floristic exchange via the BLB and/or NALB apparently prevented the formation of similar disjunctions. In the future, detailed genus-level phylogenetic analyses of Salix could provide important insights into the historical roles of the BLB and NALB as climatic filters for dispersal in lineages with different thermal tolerances (cf. [36]).

\section{Methods}

\section{Plant material, DNA extraction, and sequencing}

We sampled 55 specimens representing 51 Salix species (see Additional file 1: Table S1). The taxon sample includes nine species from the subgenera Chamaetia and Vetrix, and 47 specimens representing 41 species of subgenus Salix s.l., covering all of the subgenera and sections that have been recognized. Populus and Dovyalis were used as outgroups.

DNA was extracted from silica-gel dried leaves or from herbarium specimens using the CTAB method of Saghai-Maroof et al. [53] as modified by Doyle \& Doyle [54]. PCR was performed in $50 \mu \mathrm{l}$ volumes with the following reaction components: $1 \mu \mathrm{l}$ template DNA $(50 \mathrm{ng} / \mu \mathrm{l})$, $33.75 \mu \mathrm{l} \mathrm{H}{ }_{2} \mathrm{O}, 5 \mu \mathrm{l}$ 10X PCR buffer $\left(\mathrm{Mg}^{2+}\right.$ free), $4 \mu \mathrm{l} \mathrm{MgCl}$ $(25 \mathrm{mM}), 4 \mu \mathrm{dNTP}$ mix (2.5 mM of each nucleotide), $0.25 \mu \mathrm{l}$ TakaRa Taq $(5 \mathrm{U} / \mu \mathrm{l})$, and $1 \mu \mathrm{l}$ of each primer $(20 \mu \mathrm{M})$. The following primers were used for both amplification and sequencing of the six employed markers: "18 s-IGS" and "Bur-ETS1F" for ETS [55,56], "ITS-a" and "ITS-d" for ITS [11], "trnD ${ }^{\mathrm{GUC}} \mathrm{F}$ " and "trnT ${ }^{\mathrm{GGU} \text { " for } \operatorname{trn} D-}$ $T$ [57], "atpB-1" and "rbcL-1" for atpB-rbcL [58], " $1 \mathrm{~F}$ " and "1024R" for $r b c L$ [59], and "3F_KIM f" and "1R_KIM $\mathrm{r}$ " for matK [60]. PCR products were purified with a multifunction DNA Purification Kit (BioTeke Inc.), and then sequenced using an ABI Prism BigDye Terminator v3.1 Cycle Sequencing Kit (Perkin-Elmer Applied Biosystems) and an ABI Prism 377 Automated DNA sequencer (Perkin-Elmer Applied Biosystems).

\section{Phylogenetic analyses}

Sequences were assembled using Geneious v. 5.4 [61] and aligned with Muscle [62]. After manual correction in Geneious, regions with ambiguous alignments were excluded from the analysis. Average sequence divergences (i.e., pairwise distance) were estimated with Kimura's [63] two-parameter method in Mega v. 5.2 [64]. Numbers of indel sites, events, and diversity indices were calculated in DnaSP v. 5 [65].

Phylogenetic analyses were performed based on maximum-parsimony (MP) and maximum-likelihood (ML) criteria. MP analyses were performed with PAUP* v. 4.0b10 [66]. Gaps were treated as missing data, and characters were assumed to be unordered. Optimal trees were found using a heuristic search with the following options: tree-bisection-reconnection (TBR) branch-swapping, MulTrees option in effect, starting tree obtained via stepwise addition, trees held at each step $=5$, and MaxTrees $=100$. Branch support was estimated using bootstrapping (BS) with 2000 replicates [67]. The ML analysis employing a GTR $+\Gamma+$ I model of substitution for all datasets was run in RAxML v. 7.2.8 [68], and a bootstrap analysis of 2000 replicates was performed simultaneously (option "-f a").

\section{Tests for data incongruence and evaluation of opposing} hypotheses

Topological incongruence among partitions was tested using the incongruence length difference (ILD) test [69] in PAUP, with uninformative characters excluded and 500 replicates. Strong incongruence is defined as ILD values resulting in a $P<0.01$ [70]. Because the efficacy of the ILD test has been questioned [71-73], we also compared phylogenetic trees reconstructed from individual data sets. Well-supported ( $\mathrm{BS} \geq 70 \%$, as indicated by Hillis and Bull [74]) and conflicting clades are defined as incongruent [75]. Combined analyses were not conducted when both approaches indicated significant incongruence among the datasets.

\section{Phylogenetic network analysis}

Incongruence between the nrDNA ETS and ITS as well as combined plastid datasets were further explored using a phylogenetic network approach [76,77]. ML trees of nrDNA ETS, ITS, and combined plastid datasets were used to infer phylogenetic networks, and weakly supported branches $(\mathrm{BS}<70 \%)$ were collapsed into multifurcations. A Network consensus tree was then constructed under the galled network consensus algorithm implemented in Dendroscope v. 3.2.8 [76].

\section{Divergence time estimation}

To estimate divergence times among lineages, we employed the combined plastid $r b c L$, matK, atpB-rbcL, and $t r n D-T$ 
dataset, which successfully resolved relationships of major clades of Salix. Because a likelihood ratio test [25] rejected the assumption of rate constancy (= clock-like evolution) across the tree, we instead used the Bayesian uncorrelated log-normal relaxed molecular clock approach [41] as implemented in BEAST v. 1.5.4 [78] to estimate times of divergence and associated confidence intervals. The analysis was performed using a GTR $+\Gamma+\mathrm{I}$ substitution model with four rate categories and a Yule model prior on speciation. Posterior distributions of parameters were estimated using two independent MCMC analyses of 30,000,000 generations with a $10 \%$ burn-in. Samples from the two runs, which yielded similar results, were combined after checking convergence of the chains using Tracer v. 1.6 [79].

The Salicaceae has a rich fossil record, but reliably identifiable fossils with both catkins and leaves are rare [80]. An approximately 48-million-year-old fossil from the early Eocene in North America with well-preserved foliage and fruits was named Populus tidwellii, but its placement remains suspect because it possesses Populus-like infructescences but Salix-like leaves [81]. The immature fruits suggest that pseudoracemes may have characterized stem lineages within both Populus and Salix, and the lack of true racemes may indicate that early divergent members of the stem lineage of the Populus and Salix clades of Salicaceae s.l. were characterized by Populus-type capsules $[81,82]$. Most likely, Populus tidwellii represents the stem lineage leading to Populus and Salix [81]. Pseudosalix, another extinct, early divergent member of the stem lineage of the Populus plus Salix clade of Salicaceae s.l., was present at almost the same time [82]. Although Salix is rich in the fossil record [80] and most likely can be traced back to the early Eocene, most fossils are represented only by leaves, so it is possible that some of the Salix-like leaves represent extinct taxa such as Pseudosalix or other genera [82]. The earliest reliable Salix fossils with both catkins and leaves originate from the late Oligocene (about 23 million years ago) in Alaska and belong to subgenus Vetrix $[80,83]$. Based on the above, we used two fossil calibrations to place priors on the ages of nodes within the tree: the split between Salix and Populus (i.e., the root node of Salicaceae s.str.) was assigned a normally distributed prior with a mean of $48 \mathrm{Ma}$ and a standard deviation of 0.3 , and the divergence between the subgenera Chamaetia and Vetrix was assigned an exponential distribution prior with a mean of 1 and offset (hard bound constraint) of $23 \mathrm{Ma}$. The exponential distribution was employed here because it has a long tail of diminishing probability towards older ages [84].

\section{Character evolution analyses}

We reconstructed the evolutionary history of bud-scale morphology and stamen number by tracing the characters onto the ML tree of the combined plastid dataset (which successfully resolved relationships of major clades of Salix). Bud scale was scored as 0 (= margin free) or 1 (= margin connate), and stamen number as 0 (= more than two) or 1 (= two), and ancestral states were estimated using Mk1-model maximum-likelihood optimization in Mesquite v. 2.75 [85].

\section{Availability of supporting data}

The data sets (all sequence alignments) supporting the results of this article are available in the Dryad repository [86], [http://dx.doi.org/10.5061/dryad.qr2vv]. All sequence data is available on Genbank (http://www.ncbi.nlm.nih. gov/genbank).

\section{Additional file}

Additional file 1: Table S1. List of studied taxa, and voucher information for samples.

\section{Competing interests}

The authors declare that they have no competing interests.

\section{Authors' contributions}

JHC and YPY designed research. JW, JHC and DCW performed research. JHC analyzed data. JHC, TN, GWA and YPY wrote the paper. All authors read and approved the final manuscript.

\section{Acknowledgments}

We thank Kazumi Fujikawa of the Kochi Prefectural Makino Botanical Garden, Yoshino Hiromichi of Okayama University, Mitsuo Suzuki of the Botanical Garden of Tohoku University, Takashi Enomoto of Okayama University, the Harvard University Herbaria, and the Herbarium of Kunming Institute of Botany for providing experimental materials. This study was supported by grants from the National Natural Science Foundation of China (NSFC 31270271 and 30900085 to J. H. Chen), Yunnan Natural Science Foundation (2010CD109 to J.-H. Chen), and the Youth Innovation Promotion Association, CAS.

\section{Author details}

${ }^{1}$ Key Laboratory for Plant Biodiversity and Biogeography of East Asia, Kunming Institute of Botany, Chinese Academy of Sciences, Kunming 650201, P. R. China. ²Plant Germplasm and Genomics Center, Kunming Institute of Botany, Chinese Academy of Sciences, Kunming 650201, P. R. China. ${ }^{3}$ Institute of Tibetan Plateau Research at Kunming, Kunming Institute of Botany, Chinese Academy of Sciences, Kunming 650201, P. R. China. ${ }^{4}$ Department of Biology, University of Eastern Finland, P.O. Box 111FI-80101 Joensuu, Finland. ${ }^{5}$ Canadian Museum of Nature, Ottawa, ON, Canada, K2P 2R1.

Received: 14 September 2014 Accepted: 19 February 2015 Published online: 04 March 2015

\section{References}

1. Argus GW, Eckenwalder JE, Kiger RW. Salicaceae. In: Flora of North America Editorial Committee, editor. Flora of North America. Oxford and New York: Oxford University Press; 2010.

2. Fang Z, Zhao S, Skvortsov AK. Salicaceae. In: Wu ZY, Raven PH, Hong DY, editors. Flora of China. Beijing \& St. Louis: Science Press \& Missouri Botanical Garden Press; 1999.

3. Skvortsov AK. Willows of Russia and Adjacent Countries. Joensuu, Finland: University of Joensuu; 1999.

4. Rechinger KH. Salix taxonomy in Europe - problems, interpretations, observations. P Roy Soc Edinb B. 1992;98:1-12. 
5. Percy DM, Argus GW, Cronk QC, Fazekas AJ, Kesanakurti PR, Burgess KS, et al. Understanding the spectacular failure of DNA barcoding in willows (Salix): does this result from a trans-specific selective sweep? Mol Ecol. 2014;23:4737-56.

6. Argus GW. An experimental study of hybridization and pollination in Salix (willow). Can J Bot. 1974;52:1613-9.

7. Abdollahzadeh A, Osaloo SK, Maassoumi AA. Molecular phylogeny of the genus Salix (Salicaceae) with an emphasize to its species in Iran. Iran J Bot. 2011;17:244-53.

8. Azuma T, Kajita T, Yokoyama J, Ohashi H. Phylogenetic relationships of Salix (Salicaceae) based on rbcL sequence data. Am J Bot. 2000;87:67-75.

9. Chen JH, Sun H, Wen J, Yang YP. Molecular phylogeny of Salix L. (Salicaceae) inferred from three chloroplast datasets and its systematic implications. Taxon. 2010;59:29-37.

10. Hardig TM, Anttila CK, Brunsfeld SJ. A phylogenetic analysis of Salix (Salicaceae) based on matK and ribosomal DNA sequence data. J Bot. 2010;2010:1-12.

11. Leskinen E, Alstrom-Rapaport C. Molecular phylogeny of Salicaceae and closely related Flacourtiaceae: evidence from 5.8 S, ITS 1 and ITS 2 of the rDNA. Plant Syst Evol. 1999;215:209-27.

12. Ohashi H. Salicaceae of Japan. Sci Rep Tohoku Univ (4 Ser Biol). 2001;40:269-396.

13. Skvortsov A. Willows of the USSR. A taxonomic and geographic survey. In: Tikhomirov VN, editor. Proceedings of the Study of the Fauna and Flora of the USSR. Moscow: Nauka: Moscow Society of Naturalists, New Series, Section of Botany, 15; 1968.

14. Kimura A. De salicis subgenere Pleuradenia commentatio. Sci Rep Tohoku Univ (4 Ser Biol). 1988:39:143-7.

15. Barkalov VY, Kozyrenko MM. Phylogenetic relationships of Salix L. subg. Salix species (Salicaceae) according to sequencing data of intergenic spacers of the chloroplast genome and ITS rDNA. Russ J Genet. 2014;50:828-37.

16. Ghahremaninejad F, Khalili Z, Maassoumi AA, Mirzaie-Nodoushan H, Riahi M. Leaf epidermal features of Salix species (Salicaceae) and their systematic significance. Am J Bot. 2012;99:769-77.

17. Chen JH, Sun H, Yang YP. Cladistic analysis of the genus Salix (Salicaceae). Acata Bot Yunnan. 2008:30:1-7.

18. Dorn RD. A synopsis of American Salix. Can J Bot. 1976;54:2769-89.

19. Kimura A. Über Toisusu, eine neue Salicaceen-Gattung und die systematische Stellung derselben. Bot Mag Tokyo. 1928;42:287-90.

20. Nagamitsu T, Hoshikawa T, Kawahara T, Barkalov VY, Sabirov RN. Phylogeography and genetic structure of disjunct Salix arbutifolia populations in Japan. Popul Ecol. 2014;56:539-49.

21. Argus GW. Infrageneric classification of Salix (Salicaceae) in the New World. Syst Bot Monogr. 1997;52:1-121.

22. Trybush S, Jahodova S, Macalpine W, Karp A. A genetic study of a Salix germplasm resource reveals new insights into relationships among subgenera, sections and species. Bioenerg Res. 2008;1:67-79.

23. Degnan JH, Rosenberg NA. Gene tree discordance, phylogenetic inference and the multispecies coalescent. Trends Ecol Evol. 2009;24:332-40.

24. Zou XH, Ge S. Conflicting gene trees and phylogenomics. J Syst Evol. 2008:46:795-807.

25. Felsenstein J. Phylogenies from molecular sequences: inference and reliability. Annu Rev Genet. 1988;22:521-65.

26. Pelser PB, Kennedy AH, Tepe EJ, Shidler JB, Nordenstam B, Kadereit JW, et al. Patterns and causes of incongruence between plastid and nuclear Senecioneae (Asteraceae) phylogenies. Am J Bot. 2010;97:856-73.

27. Richardson AO, Palmer JD. Horizontal gene transfer in plants. J Exp Bot. 2007;58:1-9.

28. Calonje M, Martin-Bravo S, Dobes C, Gong W, Jordon-Thaden I, Kiefer C, et al. Non-coding nuclear DNA markers in phylogenetic reconstruction. Plant Syst Evol. 2009;282:257-80.

29. Small RL, Cronn RC, Wendel JF. Use of nuclear genes for phylogeny reconstruction in plants. Aust Syst Bot. 2004;17:145-70.

30. Futuyma DJ. Evolution. Sunderland, Massachusetts, U.S.A: Sunderland, Sinauer Associates Inc; 2005.

31. Triest L, Trung L, Haque Talukder AM, Van Puyvelde K. Nuclear cyp73 intron fragment length polymorphism supports morphological analysis of Salix species and hybrids. Plant Biosyst. 2009;143:555-63.

32. Mosseler A. Hybrid performance and species crossability relationships in willows (Salix). Can J Bot. 1990;68:2329-38.
33. Triest L. Hybridization in staminate and pistillate Salix alba and S. fragilis (Salicaceae): morphology versus RAPDs. Plant Syst Evol. 2001;226:143-54.

34. Argus GW. The genus Salix (Salicaceae) in the Southeastern United States. Syst Bot Monogr. 1986;9:1-170.

35. Tiffney BH, Manchester SR. The use of geological and paleontological evidence in evaluating plant phylogeographic hypotheses in the Northern Hemisphere Tertiary. Int J Plant Sci. 2001;162:S3-S17.

36. Vila R, Bell CD, Macniven R, Goldman-Huertas B, Ree RH, Marshall CR, et al. Phylogeny and palaeoecology of Polyommatus blue butterflies show Beringia was a climate-regulated gateway to the New World. Proc Biol Sci. 2011;278:2737-44.

37. Alsos IG, Eidesen PB, Ehrich D, Skrede I, Westergaard K, Jacobsen GH, et al. Frequent long-distance plant colonization in the changing Arctic. Science. 2007;316:1606-9.

38. Hopkins DM. The Bering Land Bridge. Stanford, California: Stanford University Press; 1967.

39. Wen J. Evolution of eastern Asian and eastern North American disjunct distributions in flowering plants. Annu Rev Ecol Syst. 1999;30:421-55.

40. Hultén E. Outline of the history of arctic and boreal biota during the quaternary period: their evolution during and after the glacial period as indicated by the equiformal progressive areas of present plant species. Stockholm: Bokförlags aktiebolaget Thule; 1937.

41. Chao N, Gong G. On the systematic postition of the Pleonandrae group in Salix. J Sichuan Forest Sci Technol. 1996;17:1-8.

42. Ding T. Origin, divergence and geographical distribution of Salicaceae. Acata Bot Yunnan. 1995;17:277-90.

43. Culley TM, Weller SG, Sakai AK. The evolution of wind pollination in angiosperms. Trends Ecol Evol. 2002;17:361-9.

44. Charlesworth D. Why are unisexual flowers associated with wind pollination and unspecialized pollinators? Am Nat. 1993;141:481-90.

45. Linder H. Morphology and The Evolution of Wind Pollination. In: Owens SJ, Rudall PJ, editors. Reproductive Biology. Kew, UK: Royal Botanical Garden; 1998. p. 123-35.

46. Elmqvist T, Ågren J, Tunlid A. Sexual dimorphism and between-year variation in flowering, fruit set and pollinator behaviour in a boreal willow. Oikos. 1988:53:58-66.

47. Kay Q. Nectar from willow catkins as a food source for blue tits. Bird Stud. 1985;32:40-4.

48. Peeters $L$, Totland $\varnothing$. Wind to insect pollination ratios and floral traits in five alpine Salix species. Can J Bot. 1999;77:556-63.

49. Regal PJ. Ecology and evolution of flowering plant dominance. Science. 1977;196:622-9.

50. Sargent RD. Floral symmetry affects speciation rates in angiosperms. Proc $R$ Soc Lon Ser B Biol Sci. 2004;271:603-8.

51. Takhtajan A. Evolutionary Trends in Flowering Plants. New York: Columbia University Press; 1991.

52. Zachos J, Pagani M, Sloan L, Thomas E, Billups K. Trends, rhythms, and aberrations in global climate 65 Ma to present. Science. 2001;292:686-93.

53. Saghai-Maroof MA, Soliman KM, Jorgensen RA, Allard RW. Ribosomal DNA spacer-length polymorphisms in barley: Mendelian inheritance, chromosomal location, and population dynamics. Proc Natl Acad Sci U S A. 1984;81:8014.

54. Doyle JJ, Doyle JL. A rapid DNA isolation procedure for small quantities of fresh leaf tissue. Phytochem Bull. 1987;19:11-5.

55. Baldwin BG, Markos S. Phylogenetic utility of the external transcribed spacer (ETS) of 18S-26S rDNA: congruence of ETS and ITS trees of Calycadenia (Compositae). Mol Phylogenet Evol. 1998;10:449-63.

56. Weeks A, Daly DC, Simpson BB. The phylogenetic history and biogeography of the frankincense and myrrh family (Burseraceae) based on nuclear and chloroplast sequence data. Mol Phylogenet Evol. 2005;35:85-101.

57. Demesure B, Sodzi N, Petit RJ. A set of universal primers for amplification of polymorphic non-coding regions of mitochondrial and chloroplast DNA in plants. Mol Ecol. 1995;4:129-34.

58. Chiang TY, Schaal BA, Peng Cl. Universal primers for amplification and sequencing a noncoding spacer between the atpB and $r b c L$ genes of chloroplast DNA. Bot Bull Acad Sinica. 1998;39:245-50.

59. Lledo MD, Crespo MB, Cameron KM, Fay MF, Chase MW. Systematics of Plumbaginaceae based upon cladistic analysis of rbcL sequence data. Syst Bot. 1998;23:21-9.

60. Janzen DH. A DNA barcode for land plants. Proc Natl Acad Sci U S A. 2009;106:12794-7. 
61. Drummond A, Ashton B, Buxton S, Cheung M, Cooper A, Duran C, et al. Geneious v5. 4. Auckland, New Zealand: Biomatters Ltd; 2011.

62. Edgar RC. MUSCLE: multiple sequence alignment with high accuracy and high throughput. Nucleic Acids Res. 2004;32:1792-7.

63. Kimura M. A simple method for estimating evolutionary rates of base substitutions through comparative studies of nucleotide sequences. J Mol Evol. 1980;16:111-20.

64. Tamura K, Peterson D, Peterson N, Stecher G, Nei M, Kumar S. MEGA5: molecular evolutionary genetics analysis using maximum likelihood, evolutionary distance, and maximum parsimony methods. Mol Biol Evol. 2011;28:2731-9.

65. Librado P, Rozas J. DnaSP v5: a software for comprehensive analysis of DNA polymorphism data. Bioinformatics. 2009;25:1451-2.

66. Swofford DL. PAUP*: Phylogenetic Analysis Using Parsimony (* and other methods). version 4. Sunderland, Massachusetts: Sinauer Associates; 2002.

67. Felsenstein J. Confidence limits on phylogenies: an approach using the bootstrap. Evolution. 1985;39:783-91.

68. Stamatakis A. RAxML-VI-HPC: maximum likelihood-based phylogenetic analyses with thousands of taxa and mixed models. Bioinformatics. 2006;22:2688-90.

69. Farris JS, Kallersjo M, Kluge AG, Bult C. Testing significance of incongruence. Cladistics. 1994;10:315-9.

70. Cunningham CW. Can three incongruence tests predict when data should be combined? Mol Biol Evol. 1997;14:733-40.

71. Hipp AL, Hall JC, Sytsma KJ. Congruence versus phylogenetic accuracy: revisiting the incongruence length difference test. Syst Biol. 2004:53:81-9.

72. Barker FK, Lutzoni FM. The utility of the incongruence length difference test. Syst Biol. 2002;51:625-37.

73. Yoder AD, Irwin JA, Payseur BA. Failure of the ILD to determine data combinability for slow loris phylogeny. Syst Biol. 2001;50:408-24.

74. Hillis DM, Bull JJ. An empirical test of bootstrapping as a method for assessing confidence in phylogenetic analysis. Syst Biol. 1993;42:182-92.

75. Zhang ZH, Li CQ, Li JH. Conflicting phylogenies of section Macrantha (Acer, Aceroideae, Sapindaceae) based on chloroplast and nuclear DNA. Syst Bot. 2010;35:801-10.

76. Huson DH, Scornavacca C. Dendroscope 3: an interactive tool for rooted phylogenetic trees and networks. Syst Biol. 2012;61:1061-7.

77. Huson DH, Scornavacca C. A survey of combinatorial methods for phylogenetic networks. Genome Biol Evol. 2010;3:23-35.

78. Drummond A, Rambaut A. BEAST: Bayesian evolutionary analysis by sampling trees. BMC Evol Biol. 2007;7:214.

79. Rambaut A, Drummond AJ. Tracer v 1.6. Available from http://beast.bio.ed. ac.uk/Tracer.

80. Collinson ME. The early fossil history of Salicaceae - a brief review. P Roy Soc Edinb B. 1992;98:155-67.

81. Manchester SR, Judd WS, Handley B. Foliage and fruits of early poplars (Salicaceae : Populus) from the eocene of Utah, Colorado, and Wyoming. Int J Plant Sci. 2006;167:897-908.

82. Boucher LD, Manchester SR, Judd WS. An extinct genus of Salicaceae based on twigs with attached flowers fruits, and foliage from the Eocene Green River Formation of Utah and Colorado, USA. Am J Bot. 2003;90:1389-99.

83. Wolfe JA. An overview of the origins of the modern vegetation and flora of the northern Rocky Mountains. Ann Mo Bot Gard. 1987;74:785-803.

84. Ho SYW, Phillips MJ. Accounting for calibration uncertainty in phylogenetic estimation of evolutionary divergence times. Syst Biol. 2009;58:367-80.

85. Maddison W, Maddison D. Mesquite: a modular system for evolutionary analysis. Version 2.73. http://mesquiteproject.org; 2014.

86. Wu J, Nyman T, Wang D-C, Argus G, Yang Y-P. Phylogeny of Salix subgenus Salix s.l. (Salicaceae): delimitation, biogeography, and reticulate evolution. Dryad Digital Repository. 2015. http://dx.doi.org/10.5061/dryad.qr2vv.

\section{Submit your next manuscript to BioMed Central and take full advantage of:}

- Convenient online submission

- Thorough peer review

- No space constraints or color figure charges

- Immediate publication on acceptance

- Inclusion in PubMed, CAS, Scopus and Google Scholar

- Research which is freely available for redistribution

Submit your manuscript at www.biomedcentral.com/submit 